\title{
Fixed Cut-Off for FEV1/FEV6 and FEV6 in Detection of Obstructive and Restric- tive Patterns
}

\author{
Rokhsareh Aghili ${ }^{1}$, Maryam Kia ${ }^{2}$, Alipasha Meysamie ${ }^{3}$, Seyed Mojtaba Aghili ${ }^{4}$, Omalbanin \\ Paknejad $^{5, *}$ \\ ${ }^{1}$ Endocrine Research Center (Firouzgar), Institute of Endocrinology and Metabolism (Hemmat Campus), Tehran University of Medical Sciences, Tehran, \\ IR Iran \\ ${ }^{2}$ Department of Internal medicine, Tehran University of Medical Sciences, Tehran, IR Iran \\ ${ }^{3}$ Department of Community and Preventive Medicine, Faculty of Medicine, Tehran University of Medical Sciences, Tehran, IR Iran \\ ${ }^{4}$ Department of Emergency Medicine, Imam Khomeini Hospital, Tehran University of Medical Sciences, Tehran, IR Iran \\ ${ }^{5}$ Division of Pulmonology, Shariati Hospital, Tehran University of Medical Sciences, Tehran, IR Iran \\ * Corresponding author:Omalbanin Paknejad, Division of Pulmonology, Shariati Hospital, POC: 1411413137, Tehran, IR Iran. Tel: +98-2184901; Fax: +98- \\ 2188633039; Email:, E-mail: opaknjd@ut.ac.ir
}

\section{A B S T R A C T}

Background:Chronic obstructive pulmonary diseases(COPD) have been defined by the Global Initiative for Chronic Obstructive Lung Disease (GOLD) as irreversible conditions which are diagnosed by fixed cut-off points of FEV1/FVC.

objective: The aim of this study was to determine the cut-off points for FEV1/FEV6 ratio and FEV6 as alternatives for FEV1/FVC and FVC in detection of airway obstruction and lung restriction, respectively.

Materials and Methods: A total of 318 Spiro metric examinations of subjects referred to Shariati hospital were analyzed. A subject was considered to have obstruction if FEV1/FVC was lower than 70\%. The restriction was defined as FVC \&lt; $80 \%$ in the absence of obstruction. The Sensitivity, specificity, positive predictive value (PPV) and negative predictive value (NPV) of FEV1/FEV6 and FEV6 were calculated.

Results: This study shows that the current cut-off points used to detect obstruction and restriction can be replaced by FEV1/FEV6 \&lt; 71\% and FEV6 \&lt; 83\%, respectively. FEV1/FEV6 had sensitivity of 95.5\% and specificity of 99.4\%; the PPV and NPVs were 99.3\% and 96.3\%. The prevalence of obstruction was $49.4 \%$. For restrictive pattern, FEV6 had sensitivity of $93 \%$, specificity of $79.5 \%$ with PPV of $18 \%$ and NPV of $99.5 \%$. The prevalence of restriction was $6.3 \%$.

Conclusions: The FEV1/FEV6 ratio can be used as a valid surrogate for FEV1/FVC in the diagnosis of airway obstruction, especially for screening purposes in high-risk populations for COPD. Moreover, FEV6 is an acceptable alternative for FVC in detection of restrictive pattern.

Keywords: Pulmonary Disease, Chronic Obstructive; Pulmonary Function Tests

Copyright @ 2013, Iranian Red Crescent Medical Journal; Published by Kowsar Corp.

Article type: Research Article; Received: 19 Sep 2012, Accepted: 02 Jan 2013; DOI:10.5812/ircmj.8163

Implication for health policy/practice/research/medical education:

Regarding the fact that achieving acceptable FVCs in spirometers are difficult in comparison to FEV6, it may be a suitable surrogate for FVC in the detection of restrictive and obstructive pulmonary diseases. On the other hand, as the variables measured in spirometers are influenced by race, this study was the first to find the best cut-off points for FEV1/FEV6 and FEV6 in the diagnosis of obstructive and restrictive pulmonary diseases in Iranian population.

Please cite this paper as:

Aghili R, Kia M, Meysamie A, Aghili SM , Paknejad O. Fixed Cut-Off for FEV1/FEV6 and FEV6 in Detection of Obstructive and Restrictive Patterns. Iran Red Cres Med J. 2013; 15(2): 152-6. DOI: 10.5812/ircmj.8163

Copyright (C) 2013, Iranian Red Crescent Medical Journal; Published by Kowsar Corp.

This is an Open Access article distributed under the terms of the Creative Commons Attribution License (http://creativecommons.org/licenses/by/3.0), which permits unrestricted use, distribution, and reproduction in any medium, provided the original work is properly cited. 


\section{Background}

Chronic obstructive pulmonary diseases (COPD) have been defined by the Global Initiative for Chronic Obstructive Lung Disease (GOLD) as irreversible conditions which are diagnosed by fixed cut-off points of FEV1/FVC $<70 \%$ (1, 2 ). In addition, FVC $<80 \%$ in a normal FEV1/FVC ratio is considered as restrictive pulmonary disease (3). Spirometer is the most common test for evaluating pulmonary function (3) which yields the above-mentioned variables (FEV1/FVC, FVC) (4-7); hence, its significance in the initial screening of COPD is emphasized (8-11). To reach an acceptable and logical FVC, two criteria have been recommended for the end of the test:

1. Subjects cannot or should not continue exhalation.

2. The volume-time curve should remain constant for at least one second $(1 \leq)$ (less than 0.0251$)$, and subjects ( $\geq 10$ years) should continue exhaling for 6 seconds or more (In children under 10 years this duration should be 3 seconds or more). In the elderly, or those with obstructive pulmonary disease, exhalation should exceed 6 seconds (up to 15 seconds), and if the curve does not touch the base, the technician should encourage the patient to reach the end of test criteria (12). Therefore, unacceptable FVCs are rather common, and in some cases they are ignored because of time constraints. If the physician oversees the absence of the end of test curve, or the short duration of exhalation, the test may be interpreted solely on the bases of the reported figures (13). Growing evidence shows that reducing the exhalation maneuver to 6 seconds (FEV6) can be a suitable substitute for FVC in the FEV1/FVC ratio (13-17). The advantages of FEV6 are as follows:

Ease in performance, both for the subject and technician $(3,18)$

Removing the limitations of accuracy in detecting very low flows at the end of the maneuvers

Reducing the duration of the spirometer

Reducing the complications of spirometer, such as syncope (19-21)

\section{Objectives}

The objective of the present study was to find the best cut-off points for FEV1/FEV6 and FEV6 in the diagnosis of obstructive and restrictive pulmonary diseases.

\section{Materials and Methods}

The population under study consisted of subjects referred to the spirometer unit of Shariati hospital and in whom spirometer was not contraindicated. Informed consent was obtained from those eligible subjects who desired to participate in the study. The subjects were included in the study up to the point where sample size was completed. The spirometers were performed by experienced technicians with the spirometer model "Viasys Health, Master Scope version 4.6” (Care, Hoechberg, Germany). Variables such as FEV1/FEV6, FEV6, FEV1/FVC, and FVC were measured and compared with the lower limit normal (LLN) values that have been specified in the NHANES III study (22). In patients in whom the diagnosis of COPD was considered according to the GOLD criteria (FEV1/FVC $<70 \%$ ), using the ROC curve, the value of FEV1/ FEV6 was determined for the highest collective sensitivity and specificity. Moreover, in individuals whom the FEV1/ FVC ratio was normal and FVC $<80 \%$ (restrictive pulmonary diseases) the best cut-off value for FEV6 was calculated by using the ROC curve. PPV and NPVs were calculated for both parameters.

\subsection{Data Analysis}

Data were analyzed with SPSS 18 . The best cut-off values were calculated for the variables using the ROC curve. The sensitivity and specificity were calculated using contingency tables. In addition, positive predictive values and negative predictive values were calculated for both indices.

\section{Results}

318 spirometers were studied; 107 (33.6\%) were female and 211 (66.4\%) were male. Their age ranged from 17-87. The mean age was $52( \pm 14.7)$. The baseline characteristics of the study population have been illustrated in Table 1 . GOLD criteria were used to detect patients with restrictive pulmonary disease in the spirometer. Based on the GOLD guideline and the degree of pulmonary involvement, these patients were classified into four subgroups (1):

Stage 1: FEV1/FVC $<70 \%$ and FEV1 $\geq 80 \%$

Stage 2 : FEV1/FVC $<70 \%$ and $50 \% \leq \mathrm{FEV} 1<80 \%$

Stage $3:$ FEV1/FVC $<70 \%$ and $30 \% \leq \mathrm{FEV} 1<50 \%$

Stage 4: FEV1/FVC $<70 \%$ and FEV1 $<30$

Table 1. Patients' Characteristics

\begin{tabular}{|c|c|c|c|c|c|c|c|c|c|c|c|}
\hline \multirow[t]{2}{*}{ Gender } & \multirow{2}{*}{ Number } & \multirow{2}{*}{$\begin{array}{l}\text { Age }, \mathrm{y}, \\
\text { Mean } \pm \text { SD }\end{array}$} & \multirow{2}{*}{$\begin{array}{l}\text { Height, cm, } \\
\text { Mean } \pm \text { SD }\end{array}$} & \multirow{2}{*}{$\begin{array}{l}\text { Weight, kg, } \\
\text { Mean } \pm \text { SD }\end{array}$} & \multicolumn{3}{|c|}{ Not Obstructed No.(\%) } & \multicolumn{3}{|c|}{ Obstructed No.(\%) } & \multirow[b]{2}{*}{ Total } \\
\hline & & & & & Normal & Restricted & Stage 1 & Stage 2 & Stage 3 & Stage 4 & \\
\hline Male & 211 & $54.2 \pm 14.5$ & $169.2 \pm 6.6$ & $75.7 \pm 14.8$ & $91(28 / 6)$ & $14(4.4)$ & $17(5.3)$ & $50(15.7)$ & $31(9.7)$ & $8(2.5)$ & $106(33.3)$ \\
\hline Female & 107 & $47.4 \pm 13.9$ & $158.4 \pm 5.6$ & $73.2 \pm 15.0$ & $50(15.7)$ & $6(1.9)$ & $12(3.8)$ & $23(7.3)$ & $13(4.1)$ & $3(1)$ & $51(16.1)$ \\
\hline Total & 318 & $51.9 \pm 14.7$ & $165.6 \pm 8.1$ & $74.9 \pm 15.0$ & $141(44.3)$ & $20(6.3)$ & $29(9.1)$ & $73(23)$ & $44(13.8)$ & $11(3.5)$ & $157(49.4)$ \\
\hline
\end{tabular}


Detection of pulmonary obstructive disease on the basis of spirometer results: (Figure 1). The FEV1/FEV6 cut-off point for detection was $71 \%$. The sensitivity and specificity of FEV1/FEV6 were $95.5 \%$ and $99.4 \%$ respectively; the PPV and NPVs were reported to be $99.3 \%$ and $96.3 \%$. The diagnostic accuracy was $97.5 \%$. The prevalence of obstruction in the study sample was $49.4 \%$ (157 out of 318 ). The findings have been illustrated in Table 2. The discordant cases were 11 in our study. The values obtained for FEV1/FVC and FEV1/ FEV6 were very close to the determined cut-off points. The detection of restrictive pulmonary disease on the basis of spirometer results: (Figure 2). FEV6 was evaluated as a substitute for FVC in the restrictive pulmonary disease in subjects whose FEV1/FVC ratio was normal. Upon analysis of the ROC curve, the obtained cut-off point for FEV6 was $83 \%$. The sensitivity and specificity of FEV6 were $93 \%$ and 79.5\%respectively; the PPV and NPVs were $18 \%$ and $99.5 \%$. The accuracy of this method was $80 \%$. The prevalence of restrictive disease was $6.3 \%$ (20 out of 318 ). The results have been presented in Table 3. The discordant cases were 2 in the current study. The values obtained for FEV6 and FVC were very close to the cut-off points determined.

Table 2. Comparison of FEV1/FEV6 with FEV1/FVC in Detection of Pulmonary Obstructive Disease

\begin{tabular}{llll}
\hline \multirow{2}{*}{ FEV1/FEV6 } & \multicolumn{2}{c}{ FEV1/FVC } & \multirow{2}{*}{ Total } \\
\cline { 2 - 3 } & Obstruction, No.(\%) & No obstruction, No. (\%) & \\
\hline Obstruction ( $<73 \%)$, No. (\%) & $146(93.6)$ & $1(0.61)$ & 147 \\
No obstruction (>=73\%), No. (\%) & $10(6.4)$ & $161(99.39)$ & 171 \\
\hline Total & $156(100)$ & $162(100)$ & 318 \\
\hline
\end{tabular}

Table 3. Comparison of FVC with FEV6 in Detection of Pulmonary Restrictive Diseases

\begin{tabular}{llll}
\hline FEV1/FEV6 & \multicolumn{2}{c}{ FVC } & Total \\
\cline { 2 - 3 } & Restriction, No. $(\%)$ & No Restriction, No. $(\%)$ & 18 \\
\hline Restriction $(<\mathbf{8 3} \%)$ & $18(90)$ & 0 & 143 \\
No Restriction $(>=83 \%)$ & $2(10)$ & $141(100)$ & 161 \\
\hline Total & $20(100)$ & $141(100)$ & 140 \\
\hline
\end{tabular}

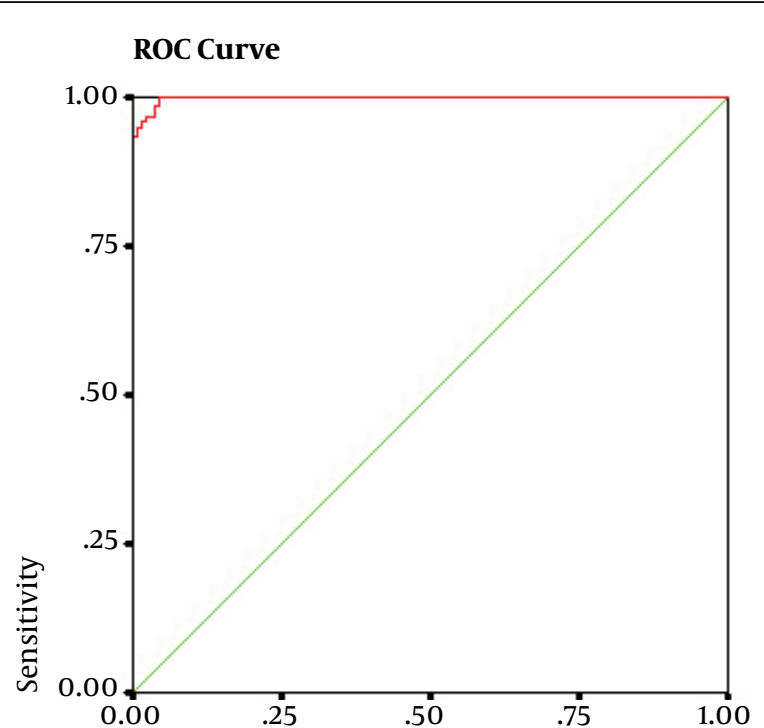

1- Specificity

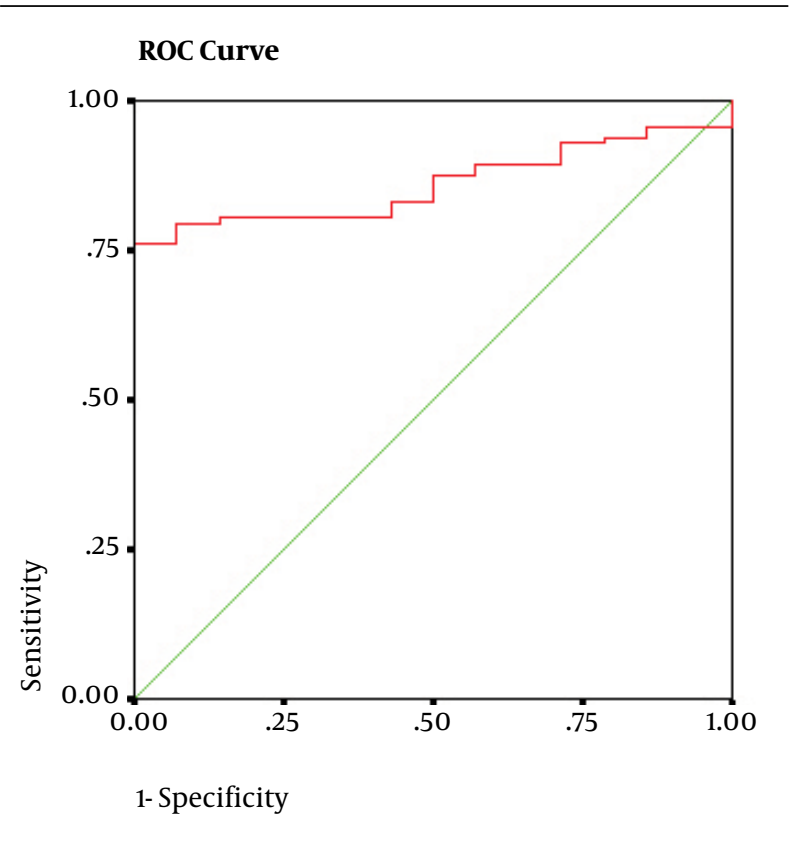

Figure 2. The ROC curve obtained for FEV6 using the GOLD standard of FVC \&lt; $80 \%$ for detection of pulmonary obstructive disease
Figure 1. The ROC curve obtained for FEV1/FEV6, using the GOLD standard of FEV1/FVC \&lt; 70\% for detection of pulmonary obstructive disease 


\section{Discussion}

Multiple studies have shown that FEV6 is a suitable surrogate for FVC in detection of the restrictive and obstructive pulmonary diseases using the LLN values in NHANES III study $(16,21,23)$. The most important objective of this study is to determine the best values of FEV6 and FEV1/ FEV6 ratio on the basis of the ROC curve in detection of the restrictive and obstructive pulmonary diseases in lieu of FVC and FEV1/FVC, respectively. The detection of pulmonary obstructive disease on the basis of spirometer results: Our results showed that the prevalence of the obstructive pulmonary disease is $49.4 \%$ in the population under study. This figure overlaps with the COPD prevalence reported in the population at-risk (people over 45 years, cigarette smokers, and those having pulmonary symptoms) that is $30-50 \%$ (3). However, cut-off points should be used with caution, because the indicators of spirometer are greatly influenced by demographic variables such as age, sex, height and race. It is noteworthy that similar studies need to be conducted using NHANES III to determine the LLN. As we lack the relevant required data in Iran, we used the LLN values obtained from the NHANES III study. The cut-off point obtained for FEV1/FEV6 in our study was $71 \%$. This value was $73 \%$ in a similar study performed by Vandevoorde et al. in 2006 (3). The prevalence of the obstructive disease in the present study was $49.4 \%$ (157 out of 318); this number was $45.9 \%$ in Vandevoorde et al. study. The sensitivity, specificity, positive and negative predictive values have been reported higher than $90 \%$ in both studies. Although the cut-off points are very close to each other in these two studies and they are widely used in order to simplify detection of disease, it is possible that the classification is incorrect. Hardie et al. study showed the age-associated reduction in FEV1/FVC and FEV1/FEV6 ratios may result in a false increase in the obstructive pulmonary disease diagnosis (24). In other words, the determined cut-off points are best applied in middle-aged persons. Eventually, despite the method used to determine the disorder; the measured values which are close to the threshold must be interpreted with caution, due to different reasons such as:

1. Spiro metric indicators change during 24 hours (25)

2. Repeatability criteria between two maneuvers recognizes a difference of $150 \mathrm{cc}$ between maximum values of FEV1/FVC as acceptable (12)

3. The coefficient of FEV1 and FVC changes in people with obstructive disease is almost twice that of ordinary people (26)

In another study conducted by Melbye et al. on 3874 acceptable spirometers performed on people $\geq 60$ years, using the ROC curve, the best FEV1/FEV6 ratio determined to replace FEV1/FVC $<70 \%$ was $73 \%$ (18). The populations in our study and Vandevoorde's were subjects referred from medical centers, while those examined in Melbye's study were chosen from a homogenous population in a north Norwegian city. In a comparison between FEV1/FEV6 and FEV1/FVC, Rosa et al. performed a study on 40 years and older people in Sao Paulo and found that FEV1/FEV6 can be a suitable substitute for FEV1/FVC in detection of the obstructive diseases, and based on a FEV1/FVC $<0.7$, the best cut-off point obtained for FEV1/FEV6 was 75\% (27). The strength of this study was the randomization of study population, and the use of reference values (LLN) extracted from the population. Despite the connection between the two aforementioned parameters, in clinical practice, there is always the possibility of discordant cases even for the best cut-off points, and in our study, this figure was very low (3.45\%). The detection of the restrictive pulmonary disease on the basis of spirometer results: In the present study, the cut-off point obtained for FEV6 was $83 \%$, that can substitute FVC $<80 \%$ in detecting the restrictive pulmonary disease. Restrictive lung disorders are associated with reduced total lung capacity (TLC), while a reduced FVC with normal FEV1/ FVC can only suggest the possibility and not the diagnosis of restrictive disease (25). A study conducted by Swanney et al. showed that spirometer algorithms cannot foresee TLC accurately, but it is widely applied in detecting restrictive disorders. They also showed that if the LLN calculated in the NHANES III study is used, FEV6 would be equivalent to FVC (21). In the study conducted by Vandevoorde et al. the prevalence of the restrictive pulmonary disease and NPV were reported as $14.9 \%$ and $99.3 \%$ respectively. These rates are appropriate for detecting restrictive pulmonary disease using FEV6. However, the foreseen values should be closely examined which can lead to an increased detection of the restrictive patterns in the elderly. In our study, the prevalence of the restrictive pulmonary disease was low (6.3\%), and the PPV was reported to be $18 \%$.

\section{Acknowledgements}

This study was funded and supported by Tehran University of Medical Sciences (TUMS).

\section{Authors' Contribution}

All authors who are listed have contributed sufficiently to the project to be included as authors: Rokhsareh Aghili, Maryam Kia, Alipasha Meysamie, Seyed Mojtaba Aghili. Sincerely, Omalbanin Paknejad, MD Assistant professor of Pulmonology Division of Pulmonology, Shariati Hospital Tehran University of Medical Sciences, Tehran, Iran.

\section{Financial Disclosure}

None declared.

\section{Funding Support}

None declared.

\section{References}

1. Fourouclas N, Li J, Gilby DC, Campbell PJ, Beer PA, Boyd EM, et al. Methylation of the suppressor of cytokine signaling 3 gene (SOCS3) in myeloproliferative disorders. Haematologica.2008;93(11):1635-44. 
2. US. Public Health Service National Heart L, Blood Institute Global initiative for chronic obstructive lung disease: global strategy for the diagnosis, management, and prevention of chronic obstructive pulmonary disease. 2004 [updated 2004; cited 2005 July and May]; Available from: www.goldcopd.com.

3. Vandevoorde J, Verbanck S, Schuermans D, Kartounian J, Vincken W. Obstructive and restrictive spirometric patterns: fixed cutoffs for FEV1/FEV6 and FEV6. Eur Respir J.2006;27(2):378-83.

4. BTS guidelines for the management of chronic obstructive pulmonary disease. The COPD Guidelines Group of the Standards of Care Committee of the BTS. Thorax.1997;52 Suppl 5:S1-28.

5. American Thoracic Society ERSTF. Standards for the diagnosis and management of patients with COPD. New York: American Thoracic Society; 2004 [updated 2004; cited 2009 March 20] Available from: www.thoracic.org/clinical/copdguidelines.

6. Pauwels RA, Buist AS, Calverley PM, Jenkins CR, Hurd SS. Global strategy for the diagnosis, management, and prevention of chronic obstructive pulmonary disease. NHLBI/WHO Global Initiative for Chronic Obstructive Lung Disease (GOLD) Workshop summary. Am J Respir Crit Care Med.2001;163(5):1256-76.

7. Siafakas NM, Vermeire P, Pride NB, Paoletti P, Gibson J, Howard P et al. Optimal assessment and management of chronic obstructive pulmonary disease (COPD). The European Respiratory Society Task Force. Eur Respir J.1995;8(8):1398-420.

8. Buffels J, Degryse J, Heyrman J, Decramer M. Office spirometry significantly improves early detection of COPD in general practice: the DIDASCO Study. Chest.2004;125(4):1394-9.

9. Lundback B, Lindberg A, Lindstrom M, Ronmark E, Jonsson AC, Jonsson E, et al. Not 15 but $50 \%$ of smokers develop COPD?--Report from the Obstructive Lung Disease in Northern Sweden Studies. Respir Med.2003;97(2):115-22.

10. Stratelis G, Jakobsson P, Molstad S, Zetterstrom O. Early detection of COPD in primary care: screening by invitation of smokers aged 40 to 55 years. Br J Gen Pract.2004;54(500):201-6.

11. Zielinski J, Bednarek M. Early detection of COPD in a high-risk population using spirometric screening. Chest.2001;119(3):731-6.

12. Miller MR, Hankinson J, Brusasco V, Burgos F, Casaburi R, Coates A, et al. Standardisation of spirometry. Eur Respir J.2005;26(2):31938.

13. Akpinar-Elci M, Fedan KB, Enright PL. FEV6 as a surrogate for FVC in detecting airways obstruction and restriction in the workplace. Eur Respir J.2006;27(2):374-7.

14. Demir T, Ikitimur HD, Koc N, Yildirim N. The role of FEV6 in the detection of airway obstruction. Respir Med.2005;99(1):103-6.

15. Gleeson S, Mitchell B, Pasquarella C, Reardon E, Falsone J, Berman
L. Comparison of FEV6 and FVC for detection of airway obstruction in a community hospital pulmonary function laboratory. Respir Med.2006;100(8):1397-401.

16. Vandevoorde J, Verbanck S, Schuermans D, Kartounian J, Vincken W. FEV1/FEV6 and FEV6 as an alternative for FEV1/FVC and FVC in the spirometric detection of airway obstruction and restriction. Chest.2005;127(5):1560-4.

17. Vandevoorde J, Verbanck S, Schuermans D, Vincken W. The role of FEV6 in the detection of airway obstruction. Respir Med.2005;99(11):1465-6.

18. Melbye H, Medbo A, Crockett A. The FEV1/FEV6 ratio is a good substitute for the FEV1/FVC ratio in the elderly. Prim Care Respir J.2006;15(5):294-8.

19. Ferguson GT, Enright PL, Buist AS, Higgins MW. Office spirom etry for lung health assessment in adults: A consensus statement from the National Lung Health Education Program. Chest.2000;117(4):1146-61.

20. Hansen JE, Sun XG, Wasserman K. Should forced expiratory volume in six seconds replace forced vital capacity to detect airway obstruction? Eur Respir J.2006;27(6):1244-50.

21. Swanney MP, Beckert LE, Frampton CM, Wallace LA, Jensen RL, Crapo RO. Validity of the American Thoracic Society and other spirometric algorithms using FVC and forced expiratory volume at $6 \mathrm{~s}$ for predicting a reduced total lung capacity. Chest.2004;126(6):1861-6.

22. Hankinson JL, Odencrantz JR, Fedan KB. Spirometric reference values from a sample of the general U.S. population. Am J Respi Crit Care Med.1999;159(1):179-87.

23. Swanney MP, Jensen RL, Crichton DA, Beckert LE, Cardno LA, Crapo RO. FEV(6) is an acceptable surrogate for FVC in the spirometric diagnosis of airway obstruction and restriction. Am J Respir Crit Care Med.2000;162(3 Pt 1):917-9.

24. Hardie JA, Buist AS, Vollmer WM, Ellingsen I, Bakke PS, Morkve O. Risk of over-diagnosis of COPD in asymptomatic elderly neversmokers. Eur Respir J.2002;20(5):1117-22.

25. Medical Section of the American Lung Association . Lung function testing: selection of reference values and interpretative strategies. American Thoracic Society. Am Rev Respir Dis.1991;144(5):1202-18.

26. Pennock BE, Rogers RM, McCaffree DR. Changes in measured spirometric indices. What is significant? Chest.1981;80(1):97-9.

27. Rosa FW, Perez-Padilla R, Camelier A, Nascimento OA, Menezes AM, Jardim JR. Efficacy of the FEV1/FEV6 ratio compared to the FEV1/FVC ratio for the diagnosis of airway obstruction in subjects aged 40 years or over. Braz J Med Biol Res.2007;40(12):1615-21. 